\title{
Double-leg isometric exercise training in older men
}

This article was published in the following Dove Press journal:

Open Access Journal of Sports Medicine

29 January 2013

Number of times this article has been viewed

\section{Anthony W Baross' \\ Jonathan D Wiles ${ }^{2}$ \\ Ian L Swaine ${ }^{2}$}

'Sport and Exercise Science, University of Northampton,

Northampton, UK; ${ }^{2}$ Sport and

Exercise Science, Canterbury Christ

Church University, Canterbury,

Kent, UK
Correspondence: Anthony W Baross Sport and Exercise Science, University of Northampton, Park campus, Boughton Green Road, Northampton NN2 7AL, UK

Tel +44 I604892 I43

Fax +44I604720636

Email tony.baross@northampton.ac.uk
Abstract: Double-leg isometric training has been demonstrated to reduce resting blood pressure in young men when using electromyographic activity (EMG) to regulate exercise intensity. This study assessed this training method in healthy older (45-60 years.) men. Initially, 35 older men performed an incremental isometric exercise test to determine the linearity of the heart rate versus percentage peak EMG $\left(\% \mathrm{EMG}_{\text {peak }}\right)$ and systolic blood pressure versus $\% \mathrm{EMG}_{\text {peak }}$ relationship. Thereafter, 20 participants were allocated to a training or control group. The training group performed three double-leg isometric sessions per week for 8 weeks, at $85 \%$ of peak heart rate. The training resulted in a significant reduction in resting systolic $(11 \pm 8 \mathrm{mmHg}, P<0.05)$ and mean arterial $(5 \pm 7 \mathrm{mmHg}, P<0.05)$ blood pressure. There was no significant change in resting systolic blood pressure for the control group or diastolic blood pressure in either group (all $P>0.05$ ). These findings show that this training method, used previously in young men, is also effective in reducing resting systolic and mean arterial blood pressure in older men.

Keywords: electromyography, resting blood pressure, heart rate

\section{Introduction}

Isometric exercise training has been shown to reduce resting blood pressure (BP). ${ }^{1-5}$ Previous isometric training studies have consistently used a given force or maximal voluntary contraction (MVC) to prescribe isometric exercise intensity. ${ }^{1-3}$ More recently, Wiles et $\mathrm{al}^{6}$ presented a novel, carefully controlled method of prescribing isometric exercise training. The method used the linear relationship between electromyographic activity (EMG) and heart rate (HR) from an incremental exercise test to set the intensity of the training program. The intensity (regulated by using a "target EMG") was selected according to a prescribed HR, allowing for more precise monitoring of cardiovascular responses at specific exercise intensities, thus allowing careful control of the response to isometric exercise during each training session.

The advantage of performing isometric exercise in this way is that even during short incremental exercise test stages (2 minutes), HR and systolic BP (SBP) reach steady state, and thus allow linear relationships to be established. ${ }^{6,7}$ Accompanying this steady-state cardiovascular response is a corresponding decrease in force generated throughout the duration of the contraction. ${ }^{7-9}$ This is in contrast to isometric exercise performed at a percentage of an individual's MVC, which has been found to stimulate a continued rise in the cardiovascular responses and EMG signal, suggesting an increase in muscle activation in an attempt to maintain a constant exercise intensity. This response has been noted in exercise intensities of $20 \%$ MVC and above ${ }^{8}$ and has 
been attributed to a continued increase in central command, as the individual attempts to maintain the required exercise intensity. ${ }^{7,9}$

This novel type of controlled training has been shown to be effective in reducing resting BP. ${ }^{5}$ However, the work underpinning this method was originally performed on young men (18-34 years), and the effectiveness of its application to older men (45-60 years) is not known. Therefore, there is a need for these methods to be explored in older men.

To date, isometric exercise training studies have either used older adults ( $\geq 60$ years) $)^{3,4,10}$ or young healthy adults ( $\leq 40$ years $)^{1,5,7}$ when investigating these relationships, with only one, to the authors' knowledge, using mid to older aged adults ( $\geq 50$ years). ${ }^{11}$ Aging is suggested to be associated with increased physiological stress during submaximal exercise, a reduced capacity to perform exercise, ${ }^{12}$ and elevated levels of resting HR and $\mathrm{BP} .{ }^{13}$ These changes have been linked to agerelated functional decline of bodily systems, including the cardiovascular and muscular skeletal systems. ${ }^{14,15}$ These agerelated deteriorations in physical capacity and cardiovascular responses may impact on the established linear relationships between HR and EMG seen in younger healthy adults. As a result, conclusions regarding the cardiovascular responses to incremental isometric exercise of older-aged (45-60 years) individuals cannot be drawn from previous research using younger subjects.

Most of the previous isometric exercise training studies using older adults ( $\geq 50$ years $)^{3,4,10,11}$ have used a handgrip mode of exercise. The double-leg training methods of Wiles et $\mathrm{al}^{5}$ have not been used in studies involving older persons. The potential advantages of one mode of isometric training over the other (handgrip versus double-leg) have not been explored, but different modes of training offer alternatives for those persons who are limited in performing exercise with either their upper or lower body. Performing an isometric training intervention using the methods of Wiles et $\mathrm{al}^{5}$ with a different participant group requires initial investigation to ensure that the method of exercise prescription from linear relationships between physiological variables is applicable in the older population.

Therefore, the purpose of this study was to: (1) explore the relationships between $\mathrm{HR}, \mathrm{EMG}$, and SBP during incremental isometric exercise in older (45-60 years) men; and (2) use data from the initial relationships to set the training intensity, during a program designed to assess the effects of double-leg isometric training on resting BP in older men.

\section{Hypothesis}

The hypothesis of this study is that there will be a significant linear relationship between \%EMG and $\mathrm{HR}$ or SBP following the incremental isometric exercise test in older (45-60 years) men and that this relationship can be used to determine the exercise intensity during an isometric training program to reduce $B P$.

\section{Materials and methods Participants}

Initial data were collected to determine the EMG and HR or SBP relationship using 35 healthy men, who were asked to complete the International Physical Activity Questionnaire and were classified as sedentary $(n=35)$. The characteristics of the group were (mean \pm standard deviation [SD]) age $54 \pm 5$ years; mass $89.4 \pm 9.4 \mathrm{~kg}$; height $178.9 \pm 5.5 \mathrm{~cm}$; body mass index (BMI) $27.9 \pm 2.3$; SBP $137 \pm 6$ mmHg; HR $70 \pm 7 \mathrm{bpm}$. They were classified as having a low level of physical activity (mean score, $494 \pm 37.8 \mathrm{MET}-\mathrm{min} /$ week) because they did not engage in regular or structured exercise sessions. ${ }^{16}$

Twenty participants of the original group volunteered to participate in the second part of this study and were randomly allocated to either 8 weeks of double-leg isometric training (TRA group; $\mathrm{n}=10$; mean $\pm \mathrm{SD}$ : age $55 \pm 6$ years; mass $89.6 \pm 3.1 \mathrm{~kg}$; height $181.2 \pm 4.4 \mathrm{~cm}$; BMI $27.3 \pm 2.2$; SBP $139 \pm 8 \mathrm{mmHg}$; HR $71 \pm 8 \mathrm{bpm}$ ) or a control group (CON group; $\mathrm{n}=10$; mean $\pm \mathrm{SD}$ : age $53 \pm 5$ years; mass $92.1 \pm 2.2 \mathrm{~kg}$; height $180.2 \pm 5.1 \mathrm{~cm}$; BMI $28.5 \pm 3.2$; SBP $139 \pm 7 \mathrm{mmHg}$; HR $69 \pm 6 \mathrm{bpm})$. The isometric training was performed at an intensity (\%EMG) equivalent to $85 \%$ of each individual's peak HR obtained during their incremental isometric exercise test. The CON group remained sedentary during the 8 week intervention period. University ethical approval was obtained prior to the start of testing, and all participants gave written informed consent prior to participation.

\section{Equipment}

All tests were performed on an isokinetic dynamometer (System 3 Pro; Biodex Medical Systems, Inc, NY, USA) and followed those procedures detailed by Wiles et al. ${ }^{6}$ Participants performed isometric double-leg (knee extension) exercise, during which EMG activity of the vastus lateralis muscle of each leg was measured, combined, and averaged. Although all three major muscles of the quadriceps femoris have been found to be active during leg extension exercise, it is suggested that the vastus lateralis muscle provides the 
most linear force-EMG relationship. ${ }^{17,18}$ The electrodes were placed in a bipolar configuration over the central portion of the muscle belly and orientated in parallel to the direction of the underlying muscle fibers. The EMG signal was amplified (gain $=300$, input impedance $=10 \mathrm{G} \Omega, \mathrm{CMRR} \geq 100 \mathrm{~dB}$ at $65 \mathrm{~Hz}$ ) by the active electrodes and directed to a high level transducer (HLT100C; Biopac Systems, Goleta, CA, USA). The EMG was further filtered using $20 \mathrm{~Hz}$ high-pass and $500 \mathrm{~Hz}$ low-pass filters, smoothed with a 1 second moving average and was root mean squared. HR was recorded continuously through a three-lead electrocardiogram using pregelled disposable electrodes (EL501; Biopac Systems). For both types of electrode, prior to placement, the skin surface was shaved and cleansed with an alcohol wipe.

To allow for precise synchronization of torque, EMG, $\mathrm{HR}$, and BP, all data generated by the dynamometer was transferred to the MP150WS Biopac data acquisition system using Acknowledge (version 3.8.1) software (Biopac Systems) via an analog output. To eliminate high frequency vibration noise, the torque signal was cleaned using a Butterworth low pass filter ${ }^{19}$ of $6 \mathrm{~Hz}$. BP was measured using a noninvasive BP monitor (NIBP100A; Biopac Systems). The monitor displays mean values of the pressure waveform using a sensor positioned cutaneously across the radial artery, with the reading being updated approximately every 10 seconds. This method has been reported to provide reliable measures of BP. ${ }^{20}$ Resting BP measures were recorded for 60 seconds following 15 minutes rest, with the participants in the supine position.

\section{Procedure}

\section{Resting measures}

Following an initial familiarization session and prior to the first incremental isometric exercise test, participants' resting measures (HR and BP) were recorded. These measures were subsequently recorded, at least 24 and no more than 48 hours after the end of week 4 and post training. Resting measures in the CON group were taken at the same time periods. All participants avoided performing strenuous exercise within 24 hours and agreed to abstain from alcohol and caffeine for a 12-hour period prior to all sessions. None of the participants were taking medication that could affect the cardiovascular variables being investigated in this study.

\section{Incremental isometric exercise test}

The first of two visits to the laboratory allowed the participants to become familiar with the equipment and test procedures. On the second visit, which was between
24 and 72 hours after the first visit, the subjects completed a double-leg incremental isometric extension exercise test. Once the participants were seated on the dynamometer with the BP monitor and electrodes attached, the dynamometer seat was adjusted appropriately for each individual so that the axis of rotation around the dynamometer shaft was adjacent to the lateral femoral condoyle of the subject's right leg. ${ }^{5}$ These individual adjustments were recorded for future tests. Once in position, the bilateral shoulder straps and an abdominal strap was adjusted and tightened to prevent any upper body movement. The participants were also asked to place their arms across their chests to stop individuals gaining extra leverage and thus increasing their MVC values and also to allow for better positioning of the BP monitor. With the knee bent at a $90^{\circ}$ angle, the legs were strapped to the knee extension/flexion attachment arm of the dynamometer, with the protective pad sitting proximal to the medial malleolus of the ankles. ${ }^{5}$ See Figure 1.

Each participant then undertook three 2-4 second maximum isometric double-leg knee extensions to determine MVC and $\mathrm{EMG}_{\text {peak }}$. There was a 60 second recovery period between contractions, with the highest of the three attempts being taken as the subject's MVC. ${ }^{7,9}$ The average root mean squared EMG for both legs was taken as the $\mathrm{EMG}_{\text {peak }}$ at the

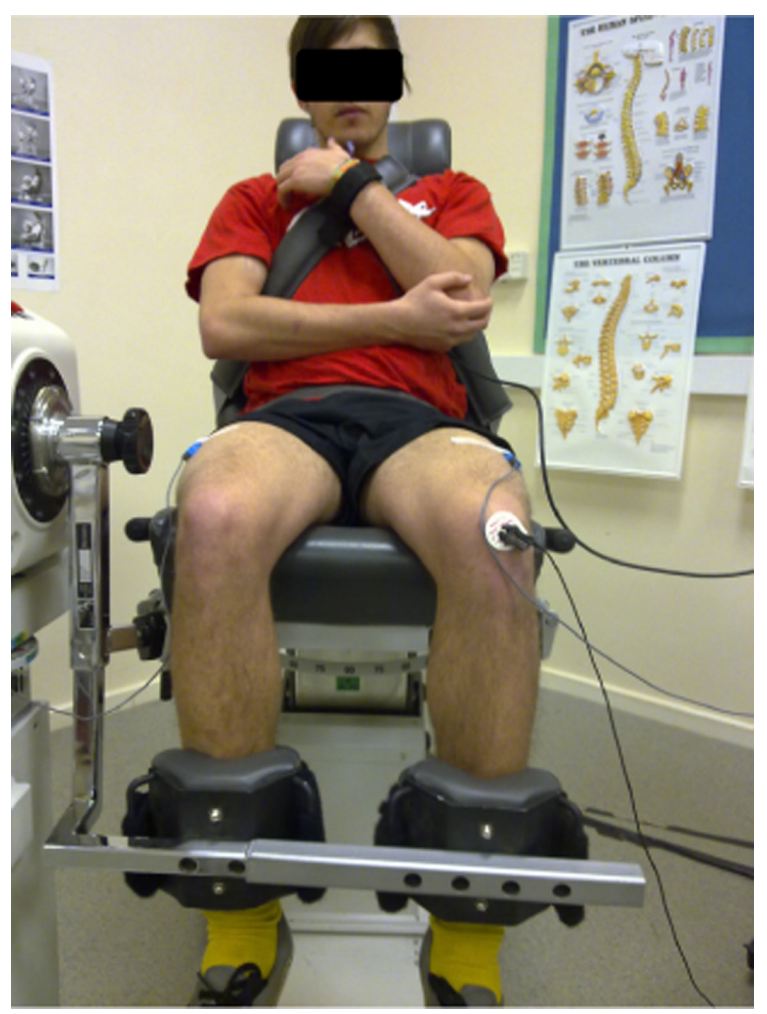

Figure I Standardized subject position during double-leg isometric testing procedures. 
point of maximum torque. After a further 5 minutes recovery, the subjects performed a continuous incremental isometric contraction at intensities of $10 \%, 15 \%, 20 \%, 25 \%$, and $30 \%$ of $\mathrm{EMG}_{\text {peak }}$ or to voluntary exhaustion. These contractions were held for 120 seconds; $\% \mathrm{EMG}_{\text {peak }}$ values were provided as visual feedback to aid the participants in maintaining the appropriate level of intensity. This was accompanied by verbal feedback and encouragement. Participants were also cautioned not to hold their breath but to breathe as normally as possible to prevent the Valsalva maneuver. The experimental setup can be seen in Figure 1.

\section{Training sessions}

Following the initial incremental isometric exercise test, participants trained 3 days per week for 8 weeks, with training sessions at least 24 hours apart. Specific target EMG values that equated to $85 \%$ of the $\mathrm{HR}_{\text {peak }}$ were used to determine each individual's training intensity. These values were interpolated from the linear relationship between HR and EMG produced from the incremental exercise test. These measures were recalculated following an intermediate incremental isometric exercise test at the end of week four. This allowed the application of progressive overload by adjustment of the training intensities associated with any adaptations which may have occurred over the initial 4 weeks of training. During all training sessions, participants performed four 2-minute isometric exercise repetitions interspaced with a 2-minute rest period. During the isometric contractions, SBP ranged from 145 to $158 \mathrm{mmHg}$. EMG, $\mathrm{HR}, \mathrm{BP}$, and torque were continually measured and recorded. Training intensity (EMG, $\mathrm{mV}$ ) was finely adjusted during the weekly training sessions if the monitored mean HR over the four 2-minute bouts deviated $( \pm 5 \%)$ from the target HR.

\section{Data analysis}

The data were assessed for the basic parametric test assumptions using Shapiro-Wilk's and Levene's tests ${ }^{21}$ and those that did not conform (BP during the incremental test) were $\log$ transformed where appropriate. Statistical analysis was performed using Microsoft Excel (Microsoft Corporation, Redmond, WA, USA), SPSS Statistics (IBM Corporation, Armonk, NY, USA) software, version 15. It has been reported ${ }^{22}$ that the magnitude of the BP reductions are related to the initial resting values. Therefore, analysis of covariance (group, TRA and CON; time, pre and post) was used to determine if there was a significant difference in the pre- and post-training BPs compared with the baseline measures, using the baseline values as the covariate.
Post hoc analysis (Bonferroni) was then used to further determine specific significant differences. Microsoft Graphpad Prism software, which uses analysis of covariance to compare the slopes and intercepts of the linear regression lines, was used to analyze the data from the incremental isometric exercise test. An alpha level of 0.05 was accepted as being significant.

\section{Results}

\section{Incremental isometric exercise test}

During each stage of the incremental test, HR reached a steady state $( \pm 5 \%)$ within the initial 60 seconds; therefore, the HR in the final minute was averaged and used in the correlation analysis. In line with previous research, ${ }^{6}$ the average SBP for the 2-minute contraction was used when undertaking the correlation analysis. The analysis of the $\mathrm{HR}$ and $\% \mathrm{EMG}_{\text {peak }}$ data demonstrated a linear relationship for all participants, $(r=0.85-1.00 ; P<0.05$ in all cases $)$. The group mean data yielded an $r$ value of $=0.99 ; P<0.01$ (Figure 2A). The relationship between SBP and $\% \mathrm{EMG}_{\text {peak }}$
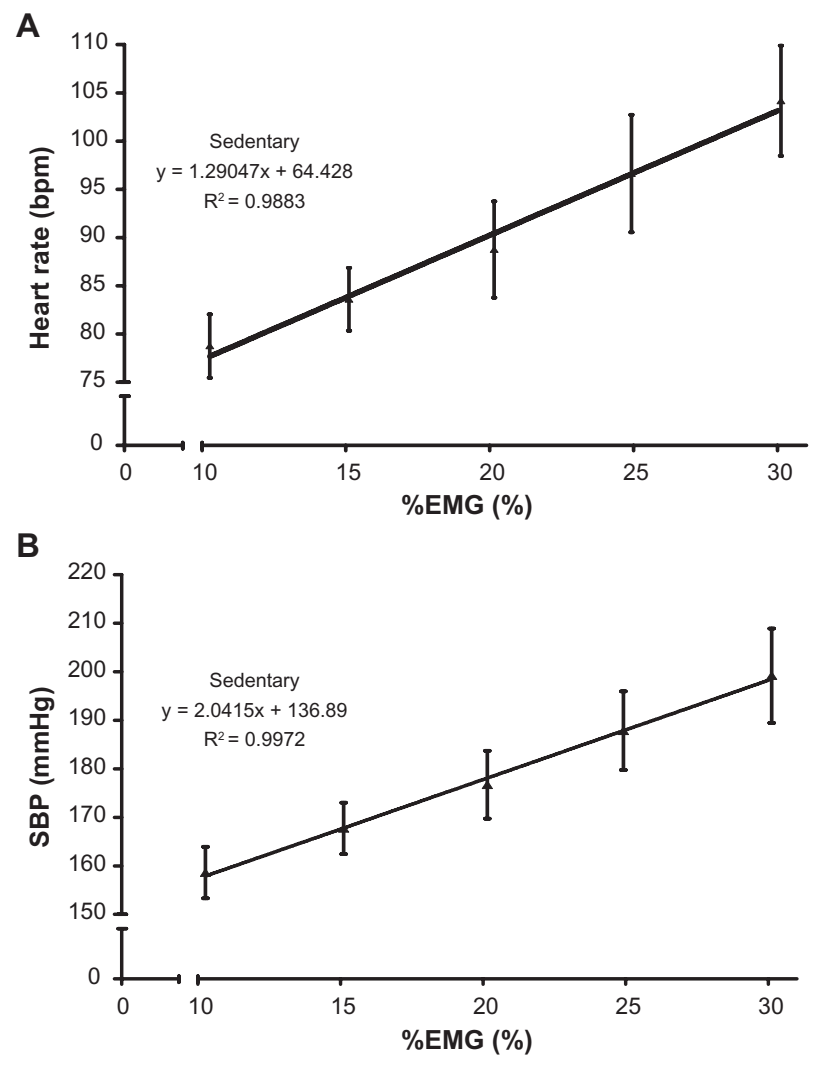

Figure 2 (A) The relationship between mean \%EMG and HR for sedentary group $(n=35)$ during leg incremental isometric exercise tests. (B) The relationship between mean \%EMG and SBP for sedentary group $(n=35)$ during leg incremental isometric exercise tests.

Abbreviations: \%EMG, percentage electromyographic activity; HR, heart rate; SBP, systolic blood pressure. 
also revealed a linear regression line in all individual cases $(r=0.88-1.00 ; P<0.05$ in all cases; group mean value: $r=0.99 ; P<0.01$ ) (Figure 2B).

\section{Baseline data}

Analysis of the baseline data for the training intervention indicates that there were no significant differences between groups (CON and TRA) for MVC, body mass, resting HR, SBP, or diastolic BP (DBP) ( $F$ values between 0.06 and $1.43 ; P>0.05$ in all cases). See Table 1 for mean values.

\section{Training intervention MVC}

There was a significant increase in MVC after isometric training compared to the CON condition (18.3 versus $\left.2.3 \mathrm{Nm}, F=10.17, P<0.05, \eta^{2}=0.79\right)$. The mean values are displayed in Table 2.

\section{$\mathrm{BP}$}

After training there were significant reductions in resting SBP in the TRA group compared with the CON group $(11 \pm 8$ versus $0.1 \pm 0.04 \mathrm{mmHg}, F=12.92, P<0.05, \eta^{2}=0.66$ ). No significant differences in DBP were observed pre/post training in either condition $\left(-1.65, F=0.31, \eta^{2}=0.69\right.$ versus $-0.1, F=1.45, \eta^{2}=0.72$ for TRA and CON respectively, $P>0.05)$. There were significant differences between the pre and post training values for mean arterial pressure (MAP) in the TRA group $(-5 \mathrm{mmHg})$ compared with the CON condition $(+0.7 \mathrm{mmHg}), F=12.41, P<0.01, \eta^{2}=0.65$. See Figure 3 for mean values. Analysis of the initial resting SBP and the changes in resting BP data following the

Table I Resting baseline data for incremental isometric test group, TRA and CON groups

\begin{tabular}{|c|c|c|c|}
\hline & \multirow{2}{*}{$\begin{array}{l}\begin{array}{l}\text { Incremental } \\
\text { isometric test }\end{array} \\
\begin{array}{l}\text { Sedentary } \\
(n=35)\end{array}\end{array}$} & \multicolumn{2}{|c|}{$\begin{array}{l}\text { Isometric exercise } \\
\text { training }\end{array}$} \\
\hline & & $\begin{array}{l}\text { CON } \\
(n=10)\end{array}$ & $\begin{array}{l}\text { TRA } \\
(n=10)\end{array}$ \\
\hline Age (years) & $54 \pm 5$ & $53 \pm 5$ & $55 \pm 6$ \\
\hline Height (cm) & $178.9 \pm 5.5$ & $\mid 80.2 \pm 5.1$ & $181 \pm 4.4$ \\
\hline Body mass (kg) & $87.4 \pm 10.6$ & $92.1 \pm 2.2$ & $89.6 \pm 3.1$ \\
\hline MVC (Nm) & $292.3 \pm 53.0$ & $304.6 \pm 88.1$ & $301.2 \pm 87.1$ \\
\hline Resting HR (bpm) & $70 \pm 7$ & $69 \pm 6$ & $71 \pm 8$ \\
\hline Resting SPB (mmHg) & $137 \pm 6$ & $139 \pm 7$ & $139 \pm 8$ \\
\hline Resting DBP (mmHg) & $81 \pm 11$ & $85 \pm 14$ & $85 \pm 7$ \\
\hline
\end{tabular}

Notes: Values are means \pm standard deviations; $P$-value $<0.05$.

Abbreviations: TRA, double-leg isometric training group; $\mathrm{CON}$, control group; MVC, maximum voluntary contraction; HR, heart rate; SBP, systolic blood pressure; DBP, diastolic blood pressure.
Table 2 Comparisons of group mean changes in measures pre and post 8-week training period

\begin{tabular}{|c|c|c|}
\hline & $\begin{array}{l}\text { TRA } \\
(\mathrm{n}=10)\end{array}$ & $\begin{array}{l}\text { CON } \\
(n=10)\end{array}$ \\
\hline$\overline{M V C}(\mathrm{Nm})$ & $18.3 \pm 26.2^{\mathrm{a}}$ & $2.3 \pm 19.9$ \\
\hline Resting SBP (mmHg) & $-11 \pm 8^{a}$ & $-0.1 \pm 4$ \\
\hline Resting DBP $(\mathrm{mmHg})$ & $-2 \pm 7$ & $-0.1 \pm 4$ \\
\hline MAP (mmHg) & $-5 \pm 7^{b}$ & $0.7 \pm 2$ \\
\hline Resting HR (bpm) & $-5 \pm 6^{a}$ & $-0.8 \pm 2$ \\
\hline
\end{tabular}

Notes: Values are means \pm standard deviations; ${ }^{2} P$-value $<0.05$; ${ }^{b}$-value $<0.01$. Abbreviations: TRA, double-leg isometric training group; CON, control group; MVC, maximum voluntary contraction; SBP, systolic blood pressure; DBP, diastolic blood pressure; MAP, mean arterial pressure; HR, heart rate.

training intervention demonstrated a linear relationship $(r$ values $=0.80 ; P<0.05)($ see Figure 4$)$.

\section{$H R$}

A significant change in the resting HR was demonstrated following the training intervention. The TRA group reduced resting $\mathrm{HR}-5 \mathrm{bpm}$ compared with the CON participants ( $-0.8 \mathrm{bpm}), F=5.58, P=0.016, \eta^{2}=0.85$. See Figure 3 for mean values.

\section{Discussion}

The purpose of this study was to initially assess the physiological responses to incremental isometric exercise in older men and then ascertain if prescription of isometric training based on these initial responses could reduce resting BP parameters in this participant group. The initial results demonstrated linear relationships between EMG and HR or SBP during incremental isometric exercise in older participants in a similar manner to previously reported responses in a younger population. ${ }^{6}$

The results of the training intervention indicate that 8 weeks of this type of training at $85 \% \mathrm{HR}_{\text {peak }}$ was sufficient to cause a significant reduction in resting SBP $(-11 \pm 8 \mathrm{mmHg})$ and MAP ( $-5 \pm 7 \mathrm{mmHg})$. There was also a significant decrease in resting HR $(5 \pm 6 \mathrm{bpm})$. However, there were no significant changes in resting DBP. Similar reductions in SBP have been reported in previous studies following this type of isometric training. Howden et $\mathrm{al}^{2}$ observed reductions of $10 \mathrm{mmHg}$ using double-leg isometric exercise over a 5-week training period. Other authors ${ }^{3,11,16}$ have reported SBP reductions of $10.0,15.4$, and $12.5 \mathrm{mmHg}$, respectively, following 8 weeks of isometric handgrip training. The only previous study to use $\%$ EMG to control exercise intensity ${ }^{5}$ also reported significant reductions in SBP $(5.2 \mathrm{mmHg})$ in healthy younger men. Two studies have found no significant changes in resting DBP. ${ }^{7,16}$ The high variability seen in the 
A

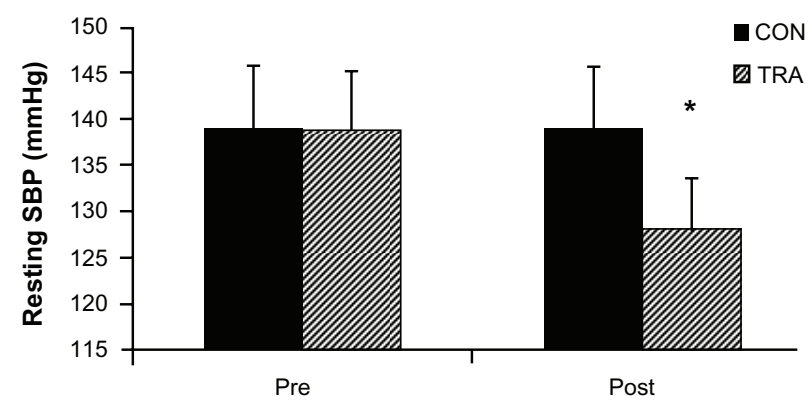

B

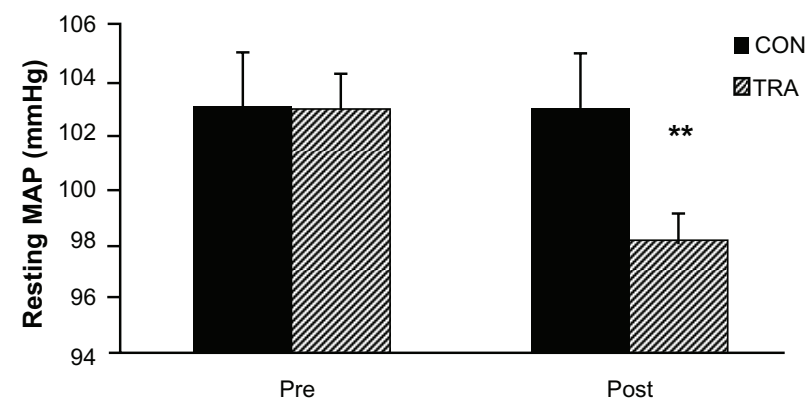

C

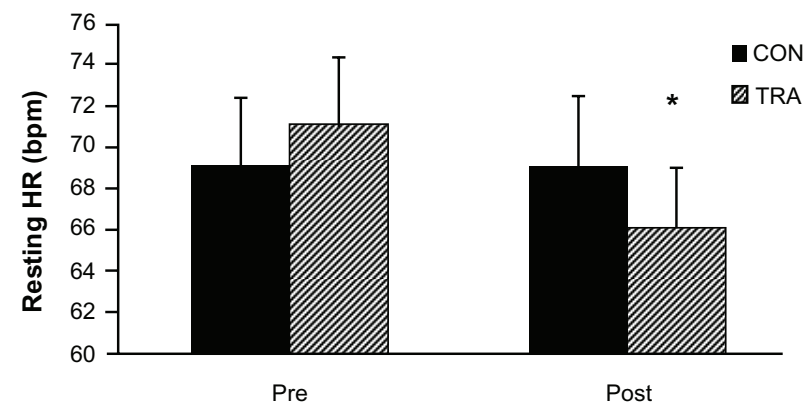

Figure 3 (A) Resting SBP for the CON and TRA groups at pre and post training. (B) Resting MAP for the CON and TRA groups at pre and post training. (C) Resting $\mathrm{HR}$ for the CON and TRA groups at pre and post training.

Notes: $* P$-value $<0.05$; $* * P$-value $<0.01$.

Abbreviations: SBP, systolic blood pressure; CON, control; TRA, double-leg isometric training; MAP, mean arterial pressure; HR, heart rate.

magnitude of the changes in resting BP following the training intervention may be associated with the participants' initial resting SBP. Data analysis of the two variables demonstrated a linear relationship. This relationship has previously been observed following isometric exercise training. ${ }^{22}$

Previous findings have suggested that the traininginduced reductions in BP may be associated with changes to autonomic function, cardiac output, baroreceptor function, and/or alterations in arterial compliance. ${ }^{1,23}$ The current understanding of the mechanisms associated with hypotension following exercise are suggested to be a combination of increased vasodilation due to presynaptic inhibition of vasoconstrictor nerves and elevated histamine receptor activation, centrally controlled mediated decreases in sympathetic

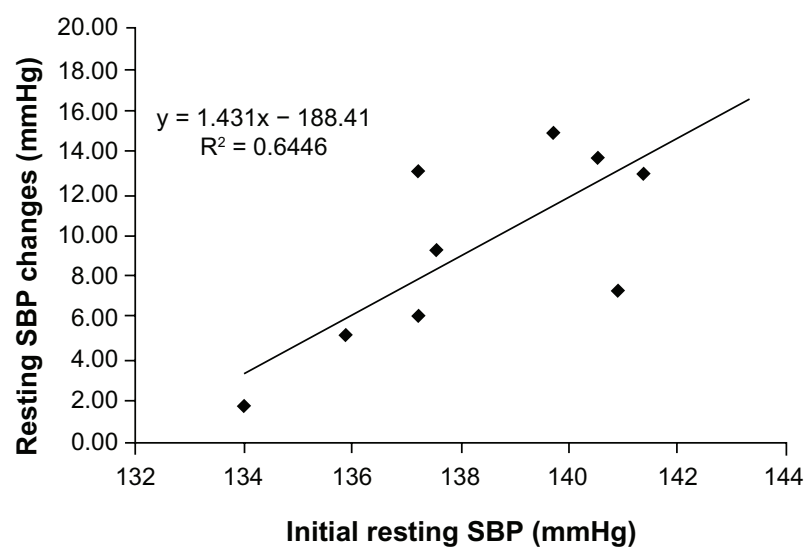

Figure 4 Regression line and plot of the initial resting SBP and changes in resting SBP for the TRA $(n=10)$ group following 8 weeks isometric exercise training. Abbreviations: SBP, systolic blood pressure; TRA, double-leg isometric training.

nerve activity, and muscle afferent induced resetting of the baroreflex, resulting in a reduced muscle sympathetic nerve activity. ${ }^{24}$ These mechanisms would alter both cardiac output and total peripheral resistance. ${ }^{2,25}$ Only one previous study incorporating isometric training has shown a reduced resting HR. ${ }^{26}$ Millar et $\mathrm{al}^{27}$ have also reported changes in the neurocardiac control following a single bout of isometric handgrip exercise which may be associated with an increase in parasympathetic activity.

Previous studies have compared the responses to isometric exercise in older and younger participants. ${ }^{28-30}$ They have shown that increases in HR during exercise are attenuated in older persons, ${ }^{29,30}$ but BP responses tend to be similar. ${ }^{28}$ The differences in the $\mathrm{HR}_{\text {peak }}$ and $\mathrm{SBP}_{\text {peak }}$ in the present study, when compared with those recorded by Wiles et $\mathrm{al}^{6}$ support this finding $\left(\mathrm{HR}_{\text {peak }}\right.$ group means, young $121.8 \pm 18.9 \mathrm{bpm}$, older $104.2 \pm 11.4 \mathrm{bpm}$; $\mathrm{SBP}_{\text {peak }}$ group means, young $181.8 \pm 14.6 \mathrm{mmHg}$, older $189.2 \pm 16.0 \mathrm{mmHg}$ ). The strong $\mathrm{HR}$ versus $\% \mathrm{EMG}_{\text {peak }}$ and $\mathrm{SBP}$ versus $\% \mathrm{EMG}_{\text {peak }}$ linear relationships identified in the present study and those shown previously in younger participants ${ }^{6}$ compare favorably ( $r=\sim 0.99, P<0.05$ in both cases). However, the slope of the relationship may differ due to the attenuated increase in HR during isometric exercise in older adults. ${ }^{29,30}$ These similarities suggest that regulation of the pressor response continues to be closely linked to muscle activity during isometric exercise, even with increasing age.

\section{Strengths and limitations}

The main strengths of the study are, firstly, that it supports the idea that the novel methods used by Wiles et al ${ }^{6}$ to determine isometric exercise intensity, is repeatable in older (45-60 years) men. Using this method to establish 
exercise intensity allows cardiovascular responses to reach a steady state during each isometric contraction. Secondly, this relationship has been used successfully in older men to determine exercise intensity for an isometric training program that significantly reduced resting BP. The main limitation of the study is that the \%EMG, HR or BP relationship was only identified in sedentary older men. Further studies need to be undertaken to determine whether this protocol can be used to determine isometric exercise intensity in habitually active older men and other populations.

\section{Conclusion}

In summary, it appears that 8 weeks of double-leg isometric training conducted at an exercise intensity of $85 \% \mathrm{HR}_{\text {peak }}$ was sufficient to cause a significant reduction in resting SBP, MAP, and resting HR in these older men. Also, it is evident that the $\mathrm{HR}$ versus $\% \mathrm{EMG}_{\text {peak }}$ and $\mathrm{SBP}$ versus $\% \mathrm{EMG}_{\text {peak }}$ relationships seen during incremental isometric exercise in younger men can be reproduced in older (45-60 years) men. This relationship can therefore be used to set the intensity of isometric training of older men, in a similar way to that of younger men.

\section{Disclosure}

The authors report no conflicts of interest in this work.

\section{References}

1. Wiley RL, Dunn CL, Cox RH, Hueppchen NA, Scott MS. Isometric exercise training lowers resting blood pressure. Med Sci Sports Exerc. 1992;24:749-754.

2. Howden R, Lightfoot T, Brown S, Swaine IL. Orthostatic tolerance and blood pressure after isometric training in humans. Exp Physiol. 2002;87:507-515.

3. Taylor AC, McCartney N, Kamath MV, Wiley RL. Isometric training lowers resting blood pressure and modulates autonomic control. Med Sci Sports Exerc. 2003;35:251-256.

4. McGowan CL, Visocchi A, Faulkner M, et al. Isometric handgrip training improves local flow mediated dilation in medicated hypertensives. Eur J Appl Physiol. 2006;98:355-362.

5. Wiles JD, Coleman DA, Swaine IL. Effects of performing isometric training at two exercise intensities in healthy young males. Eur J Appl Physiol. 2010;108:419-428.

6. Wiles JD, Allum SR, Coleman DA, Swaine IL. The relationship between heart rate, blood pressure and exercise intensity during an incremental isometric exercise test. $J$ Sports Sci. 2008;24:155-162.

7. Franke WD, Boettger CF, McLean SP. Effects of varying central command and muscle mass on the cardiovascular responses to isometric exercise. Clin Physiol. 2000;20:380-387.

8. Schibye B, Mitchell JH, Payne FC, Saltin B. Blood pressure and heart rate response to static exercise in relation to electromyographic activity and force development. Acta Physiol Scand. 1981;113:61-66.

9. Mitchell JH, Reeves DR Jr, Rogers HB, Secher NH. Epidural anaesthesia and cardiovascular responses to static exercise in man. $J$ Physiol. 1989;417:13-24.
10. McGowan CL, Levy AS, Millar PJ, et al. Acute vascular responses to isometric handgrip exercise and the effects of training in persons medicated for hypertension. Am J Physiol. 2006;291:H1797-H1802.

11. Millar PJ, Bray SR, MacDonald MJ, McCartney N. The hypotensive effects of isometric handgrip training using an inexpensive spring handgrip training device. J Cardiopulm Rehabil Prevention. 2008;28: 203-207.

12. Perini R, Fisher N, Veicsteinas A, Pendergast DR. Aerobic training and cardiovascular reponses at rest and during exercise in older men and women. Med Sci Sports Exerc. 2002;34:700-708.

13. Ferrari AU, Radaelli A, Centola M. Invited review: aging and the cardiovascular system. J Appl Physiol. 2003;95:2591-2597.

14. Vandervoort AA. Aging of the human neuromuscular system. Muscle Nerve. 2002;25:17-25.

15. Moore A, Mangoni AA, Lyons D, Jackson SHD. The cardiovascular system in the ageing patient. Brit J Clin Pharmacol. 2003;56:254-260.

16. Sargent C, Scroop G. Response: defining exercise capacity, exercise performance, and a sedentary lifestyle. Med Sci Sports Exerc. 2002;34:1692-1693.

17. Woods JJ, Bigland-Richie B. Linear and non-linear surface EMG/force relationships in human muscles: an anatomical/functional argument for the existence of both. Am J Phys Med. 1983;62:287-299.

18. Alkner BA, Tesch PA, Berg HE. Quadriceps EMG/force relationship in knee extension and leg press. Med Sci Sports Exerc. 2000;32: 459-463.

19. Bartlett R, Paton C. Biomechanical Analysis of Movement in Sport and Exercise. Leeds, UK: The British Association of Sport and Exercise Science; 1997.

20. Kumar GB, Buckley JJ, Poliac MO. Accuracy of radial artery blood pressure determination with the Vasotrac. Can J Anesth. 1999;46: 488-496.

21. Field A. Discovering Statistics: Using SPSS for Windows. London, UK: Sage; 2000.

22. Millar PJ, Bray SR, McGowan CL, MacDonald MJ, McCartney N. Effects of isometric handgrip training among people medicated for hypertension: a multilevel analysis. Blood Press Monit. 2007;12: 307-314.

23. Taylor JA, Hand GA, Johnson DG, Seals DR. Sympathoadrenalcirculatory regulation during sustained isometric exercise in young and older men. Am J Physiol. 1991;261:R1061-R1069.

24. Halliwill JR, Buck TM, Lacewell AN, Romero SA. Post-exercise hypotension and sustained post-exercise vasodilatation: what happens after we exercise? Exp Physiol. Epub August 7, 2012.

25. Fisher WJ, White MJ. Training induced adaptations in the central command and peripheral reflex components of the pressor response to isometric exercise of the human triceps surae. J Physiol. 1999;520: 621-628.

26. Baross AW, Wiles JD, Swaine I. Effects of the intensity of leg isometric training on the vasculature of trained and untrained limbs and resting blood pressure in middle-aged men. Int $J$ Vasc Med. 2012;2012:964697.

27. Millar PJ, MacDonald MJ, Bray SR, McCartney N. Isometric handgrip exercise improves acute neurocardiac regulation. Eur J Appl Physiol. 2009; 107:509-515.

28. Sagiv M, Ben-Sira D, Rudoy J. Cardiovascular responses during upright isometric dead lift in young, older, and elderly healthy men. Int J Sports Med. 1988;9:134-136.

29. Van Loan MD, Massey BH, Boileau RA, Lohman TG, Misner JE, Best PL. Age as a factor in the hemodynamic response to isometric exercise. J Sports Med. 1989;29:262-268.

30. Mayo JJ, Kravitz L. A review of the acute cardiovascular responses to resistance exercise of healthy young and older adults. $J$ Strength Cond Res. 1999;13:90-96. 


\section{Publish your work in this journal}

Open Access Journal of Sports Medicine is an international, Visit http://www.dovepress.com/testimonials.php to read real quotes peer-reviewed, open access journal publishing original research, from published authors.

reports, reviews and commentaries on all areas of sports

medicine. The manuscript management system is completely

online and includes a very quick and fair peer-review system.

Submit your manuscript here: http://www.dovepress.com/open-access-journal-of-sports-medicine-journal 